\title{
A CONCEPÇÃO DE DIREITOS HUMANOS E FUNDAMENTAIS NA TEORIA DA JUSTIÇA COMO EQUIDADE
}

\author{
Guilherme de Oliveira Feldens ${ }^{1}$ \\ Angela Kretschmann ${ }^{2}$
}

RESUMO: O presente artigo visa, em um primeiro momento, a analisar a concepção de direitos humanos feita por Rawls, para verificar se a concepção minimalista e não-metafísica apresentada pelo autor é apta a oferecer, nos dias atuais, um ideal moral que sirva de base para uma sociedade internacional democrática e justa.

PALAVRAS-CHAVE: Direitos humanos. Senso de justiça. Equidade.

\section{INTRODUÇÃo}

Na obra Law of peoples (O Direito dos povos), John Rawls apresenta uma concepção minimalista de direitos humanos, ao estender seu conceito de justiça como equidade do nível interno para um nível externo (chamado de "sociedade dos povos"). Seu projeto ético-político para o cenário internacional parte de uma utopia realista, que tem como objetivo central fazer com que as sociedades democráticas constitucionais razoavelmente justas existam como

${ }^{1}$ Doutor e mestre em Filosofia pela Universidade do Vale do Rio dos Sinos (2009), com ênfase em Ética e Filosofia Política, Filosofia do Direito, Teoria Geral do Estado e do Direito. Possui graduação (2004) em Direito e Pós-Graduação/Especialização em Processo Civil (2006) pela Universidade do Vale do Rio dos Sinos. Atua como coordenador do curso de Direito da Faculdade CESUCA, ministrando também aulas nas disciplinas de Teoria Geral do Direito, ética Geral e Profissional. E-mail: guifeldens@gmail.com

2 Angela Kretschmann: Pós-Doutora pela Westfälische Wilhelms-Universität Münster, Alemanha (ITM). Doutorado em Direito pela Universidade do Vale do Rio dos Sinos (2006). Mestrado em Direito pela Pontifícia Universidade Católica do Rio Grande do Sul (PUC/RS, 1999). Atualmente, é Professora Pesquisadora Sênior da UnB, Universidade de Brasília. Advogada (www.kre.adv.br). Integra o Quadro de Árbitros da Câmara de Arbitragem da Associação Brasileira de Propriedade Intelectual (CArb-ABPI), do Centro de Solução de Disputs em Propriedade Intelectual (CSD-PI, da ABPI), com sede em São Paulo. Autora dos livros: Direito, Criação e Tecnologia da Informação. 1. ed. São Leopoldo: Unisinos, 2012. v. 1. 120p.; Cultura, Direitos Humanos e Emancipação Latino-Americana. Florianópolis/Passo Fundo: Conceito/IMED, 2012; Índia: Muito Prazer. 2.. ed. Florianópolis: Conceito, 2009. v. 1; Direitos Intelectuais e Dignidade Humana: Revisitando o Direito Autoral na Era Digital. 1. ed. Florianópolis: Conceito, 2008; Universalidade dos Direitos Humanos e Diálogo na Complexidade de um Mundo Multicivilizacional. 1. ed. Curitiba: Juruá, 2008. v. 1; História Crítica Do Sistema Jurídico: da Prudência Antiga à Ciência Moderna. 1. ed. Rio de Janeiro: Renovar, 2006; Índia: Muito Prazer!. 1. ed. Porto Alegre: Mercado Aberto, 2003. v. 01. E-mail: b2ico@hotmail.com http://dx.doi.org/10.1590/S0101-31732017000400011 
membros de uma Sociedade dos Povos (OLIVEIRA, 2003, p. 40). Rawls acredita que o seu projeto é realista, porém, é também utópico e desejável, representando um cenário ainda não existente, mas realizável no futuro, no qual as diferenças se resolvem através de um sistema de cooperação mútua.

Nesse contexto, a partir do sexto princípio do Direito dos Povos, Rawls arrola uma lista mínima de direitos humanos baseada quase que exclusivamente na defesa das liberdades negativas. Essa concepção de direitos humanos foi objeto de muitas críticas, sinalizando uma possível incompetência do autor em enfrentar com profundidade o problema da extensão de sua teoria, fazendo com que sua teoria da justiça como equidade seja inaplicável a sociedades miseráveis, em péssima situação econômica ou com graves problemas institucionais.

Por outro lado, o modelo de justificação dos direitos humanos proposto por Rawls se afasta da visão dominante das teorias contemporâneas que buscam o fundamento desses direitos em certas características comuns dos seres humanos (SILVEIRA, 2011, p. 136). Rawls não justifica os direitos humanos por meio de "[...] nossa humanidade comum" (BUCHANAN, 2007, p. 167). Sua concepção de direitos humanos apresenta essa característica particular de estar fundamentada em uma concepção coerentista, a qual faz com que nosso juízos morais particulares estejam em harmonia com os princípios universais, fazendo com que sua lista de direitos humanos esteja de acordo com a descriçáo de nosso senso de justiça. Essa perspectiva seria apta, portanto, a estabelecer um mínimo comum de convivência justa e igualitária entre uma pluralidade de povos e organizaçóes internacionais.

O presente artigo, portanto, visa a analisar, em um primeiro momento, a concepçáo dos direitos humanos feita por Rawls, para, em um segundo momento, verificar a conformidade das críticas feitas por alguns de seus principais comentadores. Por fim, pretende-se observar se tal concepção, compreendida em uma visão ampla do pensamento filosófico do autor, é suficiente para os atuais problemas vistos no cenário político internacional.

\section{A Concepção de Direitos Humanos no Direito dos Povos}

Rawls fecha a trilogia de reflexôes sobre a justiça, defendendo a ideia de que povos razoáveis podem conviver de maneira pacífica em um mundo justo. Já na introduçáo, o autor apresenta os objetivos de seu projeto e os passos que irá seguir. Seu objetivo fundamental é estudar as possibilidades 
de estender o conceito de justiça como equidade, exposto em $A$ theory of justice e no Political liberalism, para um nível externo denominado Sociedade dos Povos (RAWLS, 1999, p. 3). Elabora ideais e princípios para a política exterior de povos razoavelmente justos, instaurando um programa de direito internacional público.

Assim, basicamente, Rawls almeja estender a sua concepção de sociedade bem-ordenada para o quadro internacional. Pretende que a organização justa da sociedade internacional seja um bem para as pessoas individualmente, possibilitando o pleno exercício das duas faculdades morais (RAWLS, 1996, p. 285), e que garanta o bem da justiça e as bases sociais do respeito mútuo, assegurando o reconhecimento público da sua condição de livre e igual (RAWLS, 1996, p. 286). Além disso, visa a que tal organização permita a exigência de um fim comum mínimo, cuja efetivação exige a cooperação de todos. Dito de outra forma, em uma sociedade bem-ordenada, deseja que os cidadãos cooperem politicamente entre si, em termos que possam ser publicamente justificados a todos, perante os valores políticos mínimos comuns (RAWLS, 1996, p. 288).

Assim, a teoria de John Raws operaria um vigoroso diálogo contra a argumentação utilitarista (a partir de princípios gerais de justiça), e também com os comunitaristas, ainda que abstraindo conscientemente de contextos concretos, pois numa ideia ampliada de justiça intenta, depois da sua Teoria da Justiça, desenvolver para o direito e a justiça uma concepção que também pode ser aplicada aos princípios e normas do direito e das relaçôes internacionais (KÜNG, 1999, p.173-174).

Entretanto, segundo alguns autores como Buchanan (2000), esse projeto exibe contradiçôes com a análise interna de construção de uma sociedade bemordenada, nos moldes apresentados em $A$ theory of justice e Political liberalism. A ampliação de sua concepçáo de justiça ao nível internacional não revelaria o profundo aspecto moral levantado por Rawls, no caso doméstico. A obra $O$ direito dos povos (The Law of Peoples) focaliza a ideia de que povos razoáveis podem conviver de maneira pacífica em um mundo justo, mas parece não estender plenamente o conceito de justiça como equidade, formulado em suas obras anteriores.

Assim, apesar de ser considerado um exemplo muito bem-elaborado de liberalismo social proposto para o âmbito internacional (BEITZ, 1999, p. 31) e um resgate dos ideais de paz perpétua, propostos por Kant, a extensão 
da justiça como equidade parece, nesses moldes, não conseguir afastar plenamente a visão tradicional de um direito internacional baseado apenas na soberania estatal, preocupado somente em construir uma noção mínima de direitos humanos (VITA, 1992, p. 92). Desse modo, a perspectiva moral indicada para o caso doméstico e a necessidade fundamental de um princípio igualitário de justiça distributiva perderiam importância e abrangência, na Sociedade dos Povos. ${ }^{3}$

No plano externo, Rawls volta a utilizar o modelo de representação da posição original para a Sociedade dos Povos, obedecendo à mesma orientação presente em $A$ theory of justice, em quase todos os seus aspectos. Porém, o que o autor parece omitir como principal diferença entre a posição original evidenciada em The law of peoples e o modelo de representação concebido originalmente por ele, em $A$ theory of justice, é uma compreensão de matriz coletiva (configurada na escolha dos representantes dos "povos" em detrimento da pessoa humana) que descaracteriza a pretensão individual de demandar e pleitear seus interesses, o forte apelo ético da justiça como equidade para o caso doméstico, representando um retrocesso em relação à construção dos princípios da justiça. Em relação à justiça internacional, Rawls apela novamente à posição original para atingir princípios de justiça no sentido de regular as relaçóes externas de sociedades bem-ordenadas umas com as outras. Portanto, não propóe um acordo entre todos os indivíduos da população mundial, mas entre os representantes de sociedades nacionais que tem como interesse fundamental manter a justiça de sua própria sociedade (FREEMAN, 2009, p. 245).

É assim que a tentativa de Rawls, em seu Direito dos Povos, permeia o "realismo utópico", incluindo, numa sociedade razoavelmente justa, o pluralismo razoável. E em relação à Sociedade dos Povos, o pluralismo razoável encontra paralelo na diversidade entre povos razoáveis, com suas diferentes culturas e tradiçóes de pensamento, tanto religiosas quanto não religiosas - o que gera uma sociedade com maior liberdade e justiça política. Por outro lado, descreve os povos liberais como possuindo três características fundamentais: a primeira é institucional (um governo democrático constitucional que serve aos interesses fundamentais); a segunda é cultural (o que foi chamado por Mill de "simpatias comuns", as quais variam entre linguagem, história, política

${ }^{3}$ Uma das razóes para essa crítica reside no fato de Rawls ser contrário a uma visão cosmopolita que tenha como objetivo final o bem-estar dos indivíduos e não a justiça. Também não defende princípios liberais estritos, com posiçôes intervencionistas, pois isso contraria o elemento essencial de tolerância, necessário para a existência de um sistema justo e estável entre povos bem-ordenados (RAWLS, 1999, p. 32). 
cultual, consciência histórica, que serão raramente preenchidas por completo, até porque as conquistas históricas e imigraçóes têm causado a mistura de culturas diferentes); enquanto a terceira requer uma firme ligação a uma concepção política (moral) de direito e justiça. Nesse último aspecto, diz que povos liberais sáo tanto razoáveis como racionais, e sua conduta racional, organizada e expressa através do voto, através da lei e política de seu governo expressa isso. Nessa perspectiva, adiante vai afirmar que a Teoria dos Povos implica a crença de que a paz universal entre as naçóes é possível, todavia, não se confunde com uma visão cosmopolita: "[...] the Law of Peoples prescribes no further target such as, for example, to raise the standard of living beyond what is necessary to sustain those institutions." (RAWLS, 1999, p. 12, 24, $103,119)$.

Dessa maneira, ao pensarem em si mesmos como livres e iguais, os povos veem os seus interesses fundamentais especificados pela sua concepção razoável de justiça política, lutando apenas para proteger a sua independência política, sua cultura livre e o bem-estar dos seus cidadãos (RAWLS, 1999, p. 35). Isso resulta no interesse de "amor-próprio", configurado no respeito adequado de um povo para consigo mesmo, baseado na sua cultura e na sua história. Essa descriçáo evidencia a ausência do valor de comunidade expresso pelo senso de justiça, no caso doméstico. $\mathrm{O}$ interesse fundamental dos representantes dos povos, no momento da escolha dos princípios de justiça, ignora o apelo moral apresentado na assimilação e defesa da justiça como equidade, no caso doméstico. Rawls parece se preocupar única e exclusivamente com a questão da tolerância e em evitar acusaçóes de etnocentrismo, ignorando que as escolhas de um Estado, povo ou, até mesmo, de um grupo de indivíduos podem afetar as vidas de outras pessoas ou de outras sociedades (BEITZ, 1992, p. 28-29). Não há uma preocupação com as consideraçóes morais necessárias para guiar o julgamento na escolha de determinadas atitudes políticas.

Diferentemente da regulação da sociedade bem-ordenada, Rawls náo pensa a sociedade internacional como um sistema de cooperação social, caracterizando as diferentes sociedades internacionais como unidades isoladas, como se não desenvolvessem entre si relacionamentos políticos e econômicos complexos, e como se tais relacionamentos não afetassem os indivíduos, nos mais diversos países (BEITZ, 1992, p. 144). Dessa maneira, o processo de escolha dos princípios de justiça rawlsiano, no âmbito internacional, náo parece ser o mais adequado para regular um sistema de cooperação 
internacional justo para com seus indivíduos. ${ }^{4}$ Deve-se, contrariamente, buscar um modo de embasar um forte senso de justiça internacional capaz de regular o julgamento de determinadas decisóes.

A preocupação de Rawls em garantir uma sociedade internacional tolerante com povos não-liberais faz com que a extensão de sua teoria da justiça não esteja baseada na pessoa humana como indivíduo, gerando a possibilidade de que os princípios fundamentais do Direito dos Povos escolhidos na posição original seja o reflexo dos interesses dominantes na sociedade, de sorte que o interesse das minorias náo seja considerado no plano internacional (BUCHANAN, 2000, p. 598). Assim, os princípios de justiça resultantes da escolha da segunda posição original podem favorecer as parcelas da população que estáo no poder e desconsiderar as minorias que existem nas sociedades (BUCHANAN, 2000, p. 697).

Esses princípios apresentados por Rawls constituem a carta básica do Direito dos Povos. Enquanto, no caso de uma sociedade fechada, os cidadáos elaboram os princípios de justiça que visam a garantir os justos termos de cooperação social, na Sociedade dos Povos, as partes selecionam diferentes formulaçôes ou interpretaçôes dos oito princípios do Direito dos Povos ${ }^{5}$, os quais são os seguintes (RAWLS, 1999, p. 47):

$\left(1^{\circ}\right)$ Os povos são livres e independentes, e a sua liberdade e independência devem ser respeitadas por outros povos; $\left(2^{\circ}\right)$ Os povos devem observar tratados e compromissos; $\left(3^{\circ}\right)$ Os povos são iguais e são partes em acordos que os obrigam; $\left(4^{\circ}\right)$ Os povos sujeitam-se ao dever de não-intervenção; $\left(5^{\circ}\right)$ Os povos têm o direito de autodefesa, mas nenhum direito de instigar à guerra por outras razões que não a autodefesa; $\left(6^{\circ}\right)$ Os povos devem honrar os direitos humanos; $\left(7^{\circ}\right)$ Os povos devem observar certas restriçōes especificadas na conduta da guerra; $\left(8^{\circ}\right)$ Os povos têm o dever de assistir

\footnotetext{
${ }^{4}$ De acordo com Sen (2009, p. 17), "[...] a posiçấo original de naçóes ou povos se limitaria de forma peculiar a lidar com muitos dos efeitos transfronteiras da ação humana. Se os efeitos do funcionamento das corporaçôes transnacionais devem ser avaliados ou analisados minuciosamente, elas têm de ser vistas pelo que são, a saber, corporaçóes que operam sem fronteiras e que tomam decisóes de negócios sobre o registro de pessoa jurídica, o domicilio fiscal e questôes contingentes semelhantes de acordo com a conveniência dos negócios. Elas dificilmente se encaixam no modelo de um povo (ou nação) que causam impactos em outros."

5 Portanto, para Rawls (2004, p. 54; 1999, p. 42), “[...] os oito princípios estâo abertos a diferentes interpretaçôes. São essas inúmeras interpretaçôes que devem ser debatidas na posição original de segundo nível. No Direito dos Povos, as dificuldades de interpretar os oito princípios que relacionei tomam o lugar dos argumentos a favor dos primeiros princípios no caso nacional. O problema de como interpretar esses princípios sempre pode ser levantado, e deve ser debatido do ponto de vista da posição original do segundo nível.”
} 
outros povos vivendo sob condiçóes desfavoráveis que os impeçam de ter um regime político e social justo ou decente.

Apesar de considerar incompleta essa lista de princípios, Rawls acredita que são os que povos bem-ordenados aceitam mutuamente como os padrốes de conduta de suas políticas externas. Assim, a partir da seleção de seus princípios de justiça, forma-se um ambiente definido pela igualdade de todos os povos, no qual todos eles estão prontos para estabelecer entre si organizaçôes cooperativas. ${ }^{6}$ Porém, a ampla liberdade na escolha dos princípios, diferentemente do que pensa Rawls, não evidenciaria necessariamente uma imposição de valores liberais. Se fosse dada ênfase à escolha por parte de representantes dos indivíduos e náo dos povos, e fossem escolhidos para o plano internacional os mesmos princípios escolhidos no caso doméstico, isso não significaria o fim da das diferenças e da diversidade cultural (normalmente, uma falsa justificativa para não ocorrer reformas institucionais necessárias e aceitáveis pela maioria da população mundial), mas sim a afirmação de uma lista mais ampla de direitos fundamentais a ser garantidos aos indivíduos (POGGE, 1989, p. 269).

Conforme expóe Audard (2007, p. 260):

Rawls está bem ciente das condiçóes históricas, econômicas e sociais que tornam as sociedades contemporâneas altamente dependentes umas das outras, de uma maneira que elas nunca foram antes. Mas por razóes metodológicas, ele toma como base um modelo de sociedade com um sistema ou estrutura fechada. Trabalhando no "ideal" ou "estrita observância teórica" (TJ: 8), ele constrói um "tipo ideal” no sentido Weberiano, concentrando-se nas características centrais que são relevantes para questóes de justiça. Essa "estrutura fechada" é a entidade mínima que não pode ser reduzida para relaçóes interpessoais, mas que formam um sistema do qual nâo podemos imaginar não sermos parte. Nós sempre somos parte de uma sociedade, qualquer que seja, nesse sentido mínimo estrutural.

Além dessas exigências, para a realização da paz democrática ser ainda mais precisa, algumas condiçóes devem ser cumpridas pelos povos, pois, na medida de seu cumprimento, a paz entre eles se torna mais segura.

\footnotetext{
${ }^{6}$ Rawls (1999, p.42, 2004, p. 54) supốe que "[...] existam três organizaçôes desse tipo: uma estruturada para assegurar o comércio justo entre os povos, outra para permitir que um povo peça empréstimo a um sistema bancário cooperativo, e a terceira, uma organização com um papel similar ao das Naçóes Unidas, à qual me referirei como Confederação de Povos (não Estados).”
} 
Assim, Rawls (2004, p. 64-65) determina que eles devem

[...] garantir certa igualdade imparcial de oportunidade, especialmente na educação. (Do contrário, nem todas as partes da sociedade podem participar dos debates da razão pública nem contribuir para as políticas sociais e econômicas); (b) Uma distribuição decente de renda e riqueza para que satisfaça a terceira condição do liberalismo: devem ser garantidos a todos os cidadãos os meios para todos os propósitos, necessários para que tirem vantagem inteligente e eficaz de suas liberdades básicas (na ausência dessa condiçáo, os que têm riqueza e renda tendem a dominar os que têm menos e a controlar cada vez mais o poder político a seu favor); (c) A sociedade como empregador de última instância por meio do governo geral ou local ou de outras políticas sociais e econômicas (a ausência de uma percepção de segurança e da oportunidade de trabalho e ocupação significativos destrói não apenas o auto-respeito dos cidadãos, mas sua percepção de serem membros da sociedade, não de simplesmente estarem presos a ela); (d) Assistência médica básica assegurada para todos os cidadãos; (e) Financiamento público das eleiçôes e maneiras de assegurar a disponibilidade de informação pública em questóes de política (uma formulação da necessidade de assegurar que os representantes e outros funcionários sejam suficientemente independentes de interesses sociais e econômicos particulares e de prover o conhecimento e a informação sobre os quais as políticas podem ser formadas e inteligentemente avaliadas pelos cidadãos.

Portanto, para estender a Sociedade dos Povos às sociedades náo-liberais, Rawls estipula como critério fundamental a garantia aos cidadãos de que tais sociedades preservarão os direitos humanos. Em acréscimo, esse sistema deve definir obrigaçôes morais aos seus cidadãos para o bom funcionamento da sociedade que compóem, firmando uma capacidade de aprendizado moral (RAWLS, 1999, p. 66). Para Rawls (1999, p. 65), entre os direitos humanos, estão o direito à vida (aos meios de subsistência e segurança); à liberdade (à liberação de escravidão, servidão e ocupação forçada, e a uma medida de liberdade de consciência suficiente para assegurar a liberdade de religião e pensamento); à propriedade (propriedade pessoal) e à igualdade formal, como expressa pelas regras da justiça natural (isto é, que casos similares devem ser tratados de maneira similar). Tal rol deixa claro, para seus críticos, que Rawls instrumentaliza os direitos humanos em torno da necessidade de tolerância liberal nas relaçóes entre povos, apresentando uma justificação afastada do estatuto da igualdade moral dos seres humanos (REIDY, 2008, p.169). Rawls ignora, em sua lista, por exemplo, alguns direitos tidos comumente 
como fundamentais, caso do Artigo $1^{\circ}$ da Declaração Universal de Direitos Humanos que traz uma concepção de pessoa naturalmente igual e livre.

Assim, além de formular uma lista mínima de direitos humanos, Rawls parece não expor uma justificação filosófica eficiente e plausível (SEN, 2009, p. 173). Sua justificativa firma base apenas na determinação de um critério mínimo de não intervenção. ${ }^{7}$ A contradição aqui soa evidente, porque os direitos humanos exercem um papel marcante para a estrutura básica de uma sociedade. A tentativa de Rawls em evitar as acusaçôes de imperialismo ocidental é o que melhor explica sua concepção minimalista de direitos humanos, no plano internacional.

Em mais de um momento, Rawls dá prioridade à autonomia dos povos em relação às revindicações e necessidades dos indivíduos (AUDARD, 2007, p. 258). Fica evidenciada, portanto, a rejeição do individualismo moral no nível global, de sorte que tal rejeição contradiz sua visão liberal de justiça (AUDARD, 2007, p. 258). Rawls, ao apresentar uma concepção minimalista de direitos humanos, náo reafirma sua defesa em favor da sua formulação original dos princípios de justiça como equidade, os quais garantiam a inviolabilidade dos indivíduos e o desenvolvimento de um senso de justiça responsável por elevar a teoria de Rawls além das concepçóes tradicionais do contrato social. O princípio da liberdade e de igualdade democrática parecem não ter uma validade universal (AUDARD, 2007, p. 259). De um ponto de vista moral, ao ignorar um estatuto de igualdade moral de todas as pessoas, Rawls parece fazer exatamente o oposto do que defendia, em $A$ theory of justice: colocar os arranjos sociais e políticos na frente de direitos e liberdades básicas para todas as pessoas.

Percebe-se que a própria teoria de Rawls inclui argumentos capazes de se contrapor ao que o Direito dos povos fundamenta, enfatizando as necessidades individuais e a inviolabilidade e dignidade dos indivíduos. O "retorno" à justiça como equidade serve para fortalecer o caráter moral da teoria rawlsiana da justiça, juntamente com seu forte acento em uma "[...] inviolabilidade fundada na justiça à que mesmo o bem da sociedade como

7 Conforme critica Sen (2009, p. 174), “[...] a noçấo de direitos humanos baseia-se em nossa humanidade compartilhada. Esses direitos náo são derivados da cidadania de qualquer país, ou da condiçấo de membro de qualquer nação, mas supostamente são pretensôes ou direitos de todo ser humano. Eles diferem, portanto, dos direitos criados constitucionalmente e garantidos para pessoas determinadas; por exemplo, o direito humano de uma pessoa nấo ser torturada ou sujeita a ataques terroristas é afirmado independentemente do país do qual esse cidadão, e também é completamente independente do que o governo desse país - ou de qualquer outro - está disposto a fornecer ou apoiar." 
um todo não pode sobrepor-se." (RAWLS, 1980, p. 3). Uma lista ampla de direitos humanos, por conseguinte, seria mais condizente com essa condição, perpassando a autonomia dos Estados e as regras políticas internacionais (AUDARD, 2007, p. 255).

Em face das críticas apresentadas, pode-se objetar que o Direito dos Povos proposto por Rawls não é suficientemente liberal, a partir de duas críticas: que os direitos humanos no Direito dos Povos não incluem os mesmos direitos garantidos por governos liberais e que apenas esse modelo de governo seria capaz de defender tais direitos propostos pela Sociedade dos Povos (RAWLS, 1999, p. 78). Em resposta, Rawls alega que os direitos humanos são uma classe de direitos que desempenham um papel importante no cenário internacional, limitando as razóes justificadoras da guerra e a autonomia interna de um regime. $^{8}$

Eles são, portanto, distintos dos direitos constitucionais de uma democracia liberal, estabelecendo um padrão necessário que limita o Direito nacional, todavia, insuficiente para garantir instituiçóes políticas e sociais justas (FREEMAN, 2001, p. 47). Tal distinção consiste numa conceituação precisa dos direitos humanos, concebidos como "[...] direitos humanos stricto sensu ou originários", distintos dos direitos fundamentais (BARRETO, 2013, p. 25) - sugerindo-se a distinçáo feita por Emmanuel Levinas, a qual indica três dimensões: primeiro, os direitos humanos originários, depois, a expansão e tipificação dos direitos humanos, através dos direitos humanos sequenciais, e, depois, os direitos do outro homem, "[...] que constituiria o cerne dos direitos humanos na contemporaneidade."

Logo, os direitos humanos defendidos por regimes liberais e decentes devem ser compreendidos como direitos universais no sentido de terem, mesmo que de maneira fraca, um efeito moral, sendo ou não sustentados localmente, de sorte que sua força política seja estendida a todos as sociedades, mesmo que fora da lei. ${ }^{9}$ Rawls não sustenta que uma sociedade decente é tão

\footnotetext{
8 Portanto, conforme Rawls (1999, p. 80, 2004, p. 105;), “[...] a classe especial dos direitos humanos tem estes três papéis: (1) seu cumprimento é condição necessária da decência das instituiçôes políticas de uma sociedade e da sua ordem jurídica; (2) seu cumprimento é suficiente para excluir a intervenção justificada e coercitiva de outros povos, por exemplo, por meio de sançôes diplomáticas e econômicas ou, em casos, graves, da força militar; (3) eles estabelecem um limite para o pluralismo entre os povos."

9 Para Bielefeldt (1999, p. 177), “[...] com a renúncia por cobrança essencial e cultural da noção de direitos humanos, abre-se espaço para que esses direitos possam ser entendidos como o cerne ou centro de um consenso de sobreposiçấo (overlapping consensus). Esse conceito foi introduzido por John Rawls e designa o papel da noção de justiça política predominante em uma sociedade moderna e liberal, na
} 
razoável e justa como uma sociedade democrática liberal, mas que ela cumpre determinadas exigências morais e políticas que impedem uma atitude de náotolerância diante delas.

É possível tratar a expressão "direitos humanos" como uma expressão que todas ou a maioria das sociedades reconhecem, entretanto, que elas definem em termos de valores de suas sociedades particulares. Como a ideia de que a concepção de direito varia de cultura para cultura é de cunho antropológico, é necessário enfrentar a questão sobre se há, de fato, um número de direitos básicos comuns em todas as culturas, apesar da aparente divergência de suas teorias, como ressalta Vincent (2001, p. 49-50): os Direitos Humanos que seriam universais fariam alguma coisa pelo Islâ, pela China, pela África e assim por diante.

A dificuldade que exibe é que, enquanto pode diminuir o etnocentrismo das declaraçôes sobre eles, abandona no processo qualquer noçâo de direitos universais. $\mathrm{O}$ autor sugere, então, três argumentos, com base na observação da açáo humana, sociológicos, que poderiam preencher o espaço entre o pluralismo cultural e a singularidade dos direitos humanos: a) primeiro, definindo a universalidade do particularismo, mas este, de fato, é um argumento fraco, na medida em que nos relembra o modelo da comunidade na qual existe uma expectativa de direitos que serão respeitados e que são locais, não globais; b) a segunda opção parece mais viável, atravessando a teoria dos direitos naturais e a tradiçấo naturalista, referida mais de uma vez como um ponto de início para o pensamento; c) a terceira sugere normas gerais sobre a sociedade como um todo, ou seja, no desenvolvimento de uma nova cultura cosmopolita, que está cada dia mais atingindo todo o mundo, devido à globalização econômica e social.

Há, com isso, uma crise advinda da modificação do espaço público, a qual não consegue compreender e administrar a realidade multiculturalista frente à utopia universalista que está na sua raiz, e torna-se manifesta a crise do político - e o multiculturalismo, como um dos frutos da crise da modernidade, traz também novas propostas. De acordo com Semprini, a parte construtiva que o multiculturalismo oferece em troca de sua crítica à modernidade

qual diferentes cosmovisôes estáo lado a lado ou em contraste. Seu pensamento concernente à justiça como centro desse consenso em uma sociedade pluralista pode ser transferido para o entendimento intercultural sobre direitos humanos. Quero destacar três aspectos decorrentes desse pensamento de Rawls: a) a reivindicação independente e crítica dos direitos humanos, b) sua limitada abrangência normativa e c) a possibilidade de sua intermediação com diferentes tradiçōes culturais." 
é a transição de um paradigma político para um paradigma ético. Como a modernidade separou as dimensóes do político e do ético, com base numa liberdade individual que só poderia ser garantida, se fosse distinta de uma igualdade política, a Ética agora exerce mais pressão sobre as respresentações coletivas e passa a influir na esfera política - o próprio sucesso do conceito de justiça (como com John Rawls, Paul Ricoeur e Philippe Van Parijs) pode ser interpretado como uma tentativa da teoria política liberal de recuperar a Ética, articulando-a ao aspecto político. O recurso maciço ao direito é outra manifestação do desenvolvimento do paradigma ético - a despeito de o direito estar ligado intrinsecamente à modernidade, pode ser estranho vêlo sendo recuperado pelos partidários do multiculturalismo. Ocorre que os multiculturalistas não ignoram a real dimensão da independência entre jurídico e político e a efetiva equidade da justiça. O papel-chave do direito seria viabilizar a coalisão entre as esferas privada e pública, esferas, aliás, consideradas muito distintas e um dos pilares da modernidade: "O direito viu-se assim chamado, muito a contragosto, a formalizar e a regulamentar a incapacidade da esfera privada de acomodar-se à mudança sociocultural." (SEMPRINI, 1999. p. 163-165).

Rawls, em sua teoria, defende que todos os povos têm os mesmos direitos, inclusive o direito de serem assistidos, quando estiverem onerados, a fim de que possam fazer parte da Sociedade dos Povos. Assim, da mesma maneira que as pessoas menos favorecidas são beneficiadas pelo princípio da diferença, os povos onerados o são pelo dever de assistência, até que todos tenham um governo liberal ou decente, não havendo razão para diminuir a diferença de riqueza entre os povos. Deve-se evitar que os cidadáos sejam estigmatizados como inferiores. Nesse sentido, no processo político internacional, os representantes dos povos devem manter a independência e a igualdade de sua sociedade em relação aos outros povos, por meio do estabelecimento de organizaçóes cooperativas e de padrốes de equidade no comércio e nas relaçóes de assistência (RAWLS, 1999, p. 116).

Assim, o oitavo princípio limita a extensão do que pode ser caracterizado como ajuda humanitária, sem transformar-se em um princípio igualitário global. Trata-se da criação de um mecanismo de ajuda para que os povos adquiram autonomia e igualdade de condiçóes, a fim de tornarem-se parte de uma Sociedade dos Povos. ${ }^{10}$ Se o dever de assistência é satisfeito e todos

${ }^{10}$ Segundo Vita (2004, p. 245), "[...] a solução que Rawls oferece ao problema de como ampliar sua concepção de justiça ao nível internacional não condiz com a perspectiva normativa mais geral que 
os povos têm um governo liberal ou decente, não há nenhuma razão para diminuir a distância entre a riqueza média dos diferentes povos.

Van Parijs acusa a existência de um paradoxo em Rawls, em relação ao dever de assistência apontado na extensão de sua teoria, pois, segundo ele, o filósofo norte-americano apresenta várias razóes para não estender o principio da diferença às relaçóes entre os povos, sendo tal proposta claramente menos igualitária que a proposta para o caso interno (PARIJS, 2001, p. 210). Beitz também afirma que Rawls entende que seu princípio da diferença não tem paralelo internacional, não havendo um critério geral no sentido de reduzir as desigualdades entre indivíduos que vivem em sociedades e culturas diferentes (BEITZ, 1999, p. 36). Novamente, Rawls parece dar prioridade à autonomia dos povos quanto à situação específica de determinados grupos ou pessoas. Ao contrário da questáo interna, para o Direito dos Povos, as desigualdades não são sempre injustas. Elas apenas ferem o ideal de justiça internacional, quando produzem efeitos danosos no âmbito da Sociedade dos povos, prejudicando o relacionamento entre seus membros. $\mathrm{O}$ aspecto fundamental é, portanto, a falta de um equilíbrio de ordem institucional entre os povos. Assim, no momento em que uma sociedade alcança uma maturidade institucional equivalente a seus pares, não há que se falar em situação de injustiça.

Dentro desse contexto, Rawls parece preocupado apenas em estabelecer padrôes econômicos e políticos justos para manter as relaçôes mercantis livres e competitivas, como se esses padrôes não fossem plenamente compatíveis com desigualdades imensas e tragédias humanas. Não há princípios substantivos (como no caso interno), nem um fundamento moral forte que alcance e combata situações concretas de injustiça. ${ }^{11}$ Ademais, Rawls também parece

sustenta sua teoria no caso doméstico: a premissa do individualismo ético é abandonada, ou pelo menos fortemente danificada. O 'individualismo ético' se refere à idéia de que é o bem-estar dos indivíduos, e não de entidades coletivas de nenhum tipo, o que constitui a última fonte de preocupaçáo moral. E considerando que a premissa do individualismo ético é derrubada, a forma da igualdade política a que $O$ direito dos povos se ajusta é a da igualdade entre povos, mais do que a igualdade entre pessoas. As implicaçôes políticas desse movimento teórico são de longo alcance: enormes desigualdades entre indivíduos são, em princípio, compatíveis com a forma de igualdade entre povos que Rawls julga ser moralmente significativa no campo internacional."

${ }^{11}$ O próprio Rawls confirma essa diferença (RAWLS, 1999, 2004, p. 150), ao afirmar que, “[...] no primeiro caso, perguntamos se haveria concordância com algum desvio da diretriz da igualdade, contanto que fosse para o benefício de todos os membros da Sociedade, e em particular dos menos favorecidos. [...] Com o Direito dos Povos, porém, as pessoas não estáo sob um, mas vários governos, e os representantes dos povos desejarão preservar a igualdade e a independência da sua própria sociedade. [...] Nesse caso, os povos maiores e menores estarão prontos a fazer contribuições maiores e menores e a aceitar retornos proporcionalmente maiores e menores." 
rejeitar um princípio democrático que permita às pessoas (e não a povos ou Estados) questionar a ordem política e econômica, caso esta favoreça exclusivamente algum membro. ${ }^{12}$

Logo, no plano internacional, Rawls mantém apenas uma espécie de "caridade" entre membros da sociedade dos povos, sem construir uma relação de verdadeiro significado moral na relação de distribuição e ajuda humanitária. Conforme salienta Pogge (2007, p. 76),

[...] a utopia de Rawls é falha, então, por excluir a preocupação de manter a justiça de fundo global, e por excluir qualquer preferência para a estruturaçấo da economia global de forma que as desigualdades sejam moderadas e permita que a sociedade, especialmente os mais fracos economicamente, a crescer. Esta falha também marca o julgamento implícito que o livro faz do nosso mundo, onde, no meio da abundância, um terço de todas as mortes é devido à desnutrição e doenças são evitáveis. A versão de Rawls nos engana ao apontar o nosso fracasso moral atual como um caso de assistência insuficiente aos pobres, quando na realidade consiste na imposição sobre eles de uma forma global enviesada que dificulta e impede o seu desenvolvimento.

A declaração de Pogge reforça a ideia da diferença pela qual Rawls trata o combate às desigualdades, na sociedade fechada e no Direito dos Povos, já que o chamado dever de assistência não parece ser suficiente para abordar as desigualdades e estabelecer um forte senso moral de justiça entre os povos. Pode-se sustentar, então, que tanto o princípio da diferença quanto o dever de assistência entre os povos têm como objetivo atingir uma autonomia política. Porém, enquanto o primeiro visa a garantir a autonomia aos indivíduos, o dever de assistência projeta esse objetivo para os povos e Estados. Nesse aspecto, Rawls parece ignorar que apenas as pessoas individualmente são possuidoras de dignidade e que (conforme o próprio autor afirma, em $A$ theory of justice) os planos de vida e as condiçôes materiais das pessoas são afetadas pelas contingências concretas do local em que nasceram. Garantir, portanto,

\footnotetext{
${ }^{12}$ Vita (1992, p. 21) questiona esse aspecto da seguinte forma: “[...] em que sentido podemos julgar os membros individuais de um povo - por exemplo, mulheres pobres e trabalhadores rurais- como responsáveis pelas decisóes tomadas em sua sociedade a respeito de desenvolvimento econômico e social ou controle demográfico? São os governos os que tomam decisôes desse tipo e náo individualidades fictícias como 'povos'. Se quiséssemos que as noçôes de escolha e responsabilidade assumissem, na sociedade internacional, o mesmo papel moral que jogam no exemplo 'Wilt Chamberlain' de Nozick, entâo deveríamos estar preparados, no mínimo, para exigir que os povos fossem democraticamente governados. E Rawls claramente não quer chegar tão longe."
} 
plena autonomia a um povo ou a uma sociedade náo garante por si só justiça aos indivíduos.

Como para Rawls o que é determinante no desempenho de um país é a sua cultura política e não a situação de seus recursos naturais, não é produtivo e justo o princípio distributivo global entre os diversos povos, pois não estabelece um objetivo específico e um limite para o constante auxílio (RAWLS, 1999, p. 117).

Segundo Rawls (1999, p. 155),

[...] o ponto crucial é que o papel do dever de assistência é ajudar sociedades oneradas a tornarem-se membros plenos da Sociedade dos Povos e capazes de determinar o caminho do seu futuro por si mesmas. Trata-se de um princípio de transição, da mesma maneira que o princípio da poupança real ao longo do tempo em uma sociedade nacional é um princípio de transição. Como foi explicado no parágrafo 15.2, a poupança real tem o fim de estabelecer o fundamento para uma estrutura social básica justa, ponto em que pode cessar. Na sociedade do Direito dos Povos, o dever de assistência é válido até que todas as sociedades tenham alcançado instituiçóes básicas liberais ou decentes justas. Tanto o dever de poupança real como o dever de assistência são definidos por um alvo além do qual não são mais exigíveis. Eles garantem os elementos essenciais da autonomia politica: a autonomia política dos povos liberais e decentes iguais e livres da Sociedade dos Povos.

De maneira similar ao caso interno, o ideal de razão pública dos povos é alcançado sempre que executivos, legisladores e outros funcionários governamentais agem de acordo com os princípios do Direito dos Povos, explicando a outros povos as suas razóes de política externa (RAWLS, 1999, p. 57). Já os cidadãos devem pensar em si mesmos como se fossem executivos e legisladores, e questionar que políticas exteriores seriam mais razoáveis. Rawls, em consequência, propóe a criação de novas instituiçóes e práticas, as quais sirvam como uma espécie de centro confederativo para a opinião política dos povos bem-ordenados em relação aos regimes opressores e expansionistas e a violaçáo dos direitos humanos. Com a criação de centros de discussão nesses moldes, os povos bem-ordenados podem definir programas que visem a pressionar os regimes fora da lei a rever sua conduta, discutindo, por meio de um julgamento político, a possibilidade de impor recusa de assistência e de práticas cooperativas mutuamente benéficas a esses regimes (RAWLS, 1999, p. 94). 


\section{O Debate entre Rawls e seus Críticos: A razoabilidade da Promoçáo Universal dos Direitos Humanos}

A teoria da justiça de Rawls, em termos de aplicação interna, exige um conjunto extenso de instituiçóes que determina a estrutura básica de uma sociedade plenamente justa (SEN, 2009, p. 56), fato que confirma o abandono, por parte do autor, de seus próprios princípios de justiça, quando se trata de avaliar a forma de pensar sobre a justiça global, e não siga na direção fantasiosa de querer um Estado global. ${ }^{13}$ Sua ideia de justiça internacional exibe uma estrutura muito frágil, resumindo-se a uma espécie de negociação entre os representantes dos diferentes países sobre algumas questôes muito elementares de civilidade e humanidade - "[...] que podem ser vistas como características muito limitadas da justiça.” (SEN, 2009, p. 56). Nesse sentido, Rawls não tenta derivar princípios de justiça que possam emanar dessas negociações, contudo, concentra-se, em vez disso, em certos princípios gerais de comportamento humanitário (SEN, 2009, p. 56).

Além disso, o próprio pluralismo defendido por Rawls, em suas obras anteriores, precisa de um tratamento que ultrapasse os limites estabelecidos pelos poderes e arranjos políticos instituídos formalmente. Os debates globais ultrapassam os limites representativos das naçôes ou lideranças políticas, estabelecendo outros critérios de formulação. ${ }^{14} \mathrm{~A}$ relevância das discussões globais não está condicionada à existência de um Estado global ou de um fórum planetário bem-organizado para gerar gigantescos acordos institucionais entre naçóes ou coletividades, pois diferentes pessoas náo precisam realizar

\footnotetext{
${ }^{13}$ Segundo Amartya Sen (2009, p. 55), “[...] a pergunta que temos de fazer aqui é: quais reformas internacionais precisamos fazer para tornar o mundo um pouco menos injusto? No entanto, esse tipo de discussáo sobre a melhoria da justiça, em geral, e do alargamento da justiça global, em particular, pareceria mera 'conversa fiada' para aqueles que estão convencidos, pela alegação hobbesiana - e rawlsiana - , de que necessitamos de um Estado soberano para aplicar os princípios de justiça através da escolha de um conjunto perfeito de instituições: essa é uma implicação direta da consideração de questôes de justiça dentro da estrutura do institucionalismo transcendental. A justiça global perfeita, por meio de um conjunto de instituiçóes impecavelmente justo, mesmo que tal coisa pudesse ser identificada, sem dúvida exigiria um Estado global soberano, e na ausência desse estado, as questôes de justiça global pareceriam intratáveis aos transcendentalistas."

${ }^{14}$ Conforme Sen (2009, p. 173-174), “[...] os correlatos comportamentais do comercio global, da cultura global, da política global, da filantropia global e mesmo dos protestos globais baseiam-se nas relaçôes diretas entre os seres humanos - com seus próprios padróes, suas respectivas inclusóes e prioridades relacionadas com uma variedade de classificaçôes. Essas éticas podem, naturalmente, ser apoiadas ou minuciosamente analisadas ou criticadas de diferentes maneiras, até mesmo invocandose outras relaçôes intergrupais, mas não precisam limitar-se às relaçôes internacionais, nem mesmo ser por elas guiadas. [...] Coletividades de muitos tipos diferentes podem ser invocadas . A justiça internacional simplesmente não é adequada para a justiça global."
} 
operaçóes além-fronteiras apenas por meio de relaçôes internacionais e nem pertencer a linhas de divisão (povos, naçóes etc.) pré-determinadas (SEN, 2009, p. 172).

Essa crítica se intensificou ainda mais com o processo de globalização, no qual perdem significado relaçóes marcadas por conceitos geográficos e culturais específicos, ou por interesses de grupos dominantes, em prol de relacionamentos caracterizados pela cooperação. Desse modo, a abordagem sobre a justiça internacional não pode ser dissociada da participação popular. A ideia de justiça, então, deve desconsiderar os limites locais e ter uma caracterização individual, pois os arranjos institucionais perdem cada vez mais poder de influência diante das complexas redes políticas e econômicas formadas em nível global. Ademais, a distinção entre assuntos internos e internacionais já não é mais clara como antigamente, pois existem questóes que envolvem situaçóes além de fronteiras ou demarcações locais (HELD, 2000, p. 307).

É fundamental, por conseguinte, estabelecer um padrão de justiça que reconheça a existência de uma rede de relacionamentos entre indivíduos e grupos de indivíduos, capaz de influenciar uns aos outros e afetar as perspectivas das pessoas que vivem dentro de seus limites. Esse contexto necessita de um senso de justiça comum, o qual permita a percepção e a valorização dessas relaçóes, ao mesmo tempo em que aponte as deficiências de um modelo institucional que ignora o individualismo ético substantivo capaz de levar em conta as condiçóes de vida dos membros da sociedade global. ${ }^{15}$ Diante de uma realidade marcada pela pluralidade e pela diversidade humana, é cada vez mais necessário acentuar o interesse pela justiça, ouvindo "[...] as vozes dissidentes em cada sociedade." (SEN, 2009, p. 200).

Toda e qualquer teoria da justiça deve levar em consideração o mundo inteiro, porque não é apenas "[...] a nossos vizinhos locais que devemos alguma ajuda para superar a injustiça.” (SEN, 2009, p. 206). Cada vez mais os povos se ligam não apenas por relaçôes econômica, sociais e políticas, mas também pelas preocupaçóes com a injustiça e a violência que os desafiam

${ }^{15}$ Conforme expóe Sen (2009, p. 56), “[...] a teoria da justiça, assim como formulada no âmbito do institucionalismo transcendental hoje dominante, transforma muitas das questóes mais relevantes da justiça em retórica vazia - mesmo que seja reconhecida como uma retórica bem-intencionada. Quando as pessoas em todo o mundo se mobilizam para obter mais justiça global - e enfatizo aqui o termo comparativo 'mais' - , não estâo clamando por algum tipo de humanitarismo mínimo. Também não estão se mobilizando a favor de uma sociedade mundial perfeitamente justa, mas apenas pela eliminação de alguns arranjos afrontosamente injustos, para melhorar a justiça global." 
frequentemente. Portanto, uma abordagem adequada sobre a justiça não pode se concentrar somente na determinação de arranjos institucionais justos entre diferentes povos, mas tentar de alguma forma buscar um padrão possível de participação e união capaz de ir além das fronteiras e de levar em conta o interesse de todos.

Porém, essas críticas ignoram o fato de que Rawls, através de um argumento circular presente em seus textos anteriores a The law of peoples, define o senso de justiça dos cidadáos como elemento social essencial para a construçáo de um sistema equitativo de cooperaçáo. Determina que a maneira como o sistema social se organiza define o tipo de pessoas que seremos. Nesse argumento, portanto, encontra-se, de um lado uma teoria psicológica que tem por objetivo definir a cooperação social como etapa maior do critério moral e, de outro lado, uma teoria social que vê na ética substancial o instrumento necessário a garantir a estabilidade e a coesão social. E essa forma de coesão social proposta por Rawls possibilita fundamentar uma concepção de Direitos humanos singular. Essa circularidade configura o liberalismo político de Rawls como uma teoria embasada em um coerentismo holístico de influência hegeliana (AUDARD, 2007, p. 56).

Pensada desse modo, analisando-se a concepçáo de direitos humanos do autor inserida dentro desse contexto filosófico mais amplo, a justificação da teoria dos direitos humanos apresentada por Rawls pode ser compreendida por meio da construção de um entendimento público embasado na reflexão e na argumentação. Essa posição seria plenamente coerente com a proposta de Rawls, já que o foco principal de sua teoria é uma proposta de justiça voltada para as instituiçóes políticas e jurídicas, configurando uma ontologia holística social (AUDARD, 2007, p. 56). Ela não fundamenta um mero modus vivendi, uma vez que traz ligada a si a ideia de reciprocidade e de que a capacidade de ter um senso de justiça baseado na reciprocidade é uma condição da sociabilidade humana (RAWLS, 1999, p. 435). Na teoria da justiça como equidade, as pessoas passam a compreender profundamente os princípios e ideais de justiça e, consequentemente, as normas éticas deixam de ser vistas como restrição e passam a abranger uma concepção coerente de reciprocidade e cooperação. O senso de justiça representa, consequentemente, a extensão dos vínculos naturais das pessoas e a preocupação com a justiça e o bem de todos, independentemente do local ou da nação em que se encontram. É justamente essa ética substantiva enfocada pelo autor um forte argumento para fundamentar uma concepção 
capaz de atingir um padrão humanitário que vá além das fronteiras e que leve em conta o interesse de todos.

\section{Conclusão}

Foi possível perceber que a justiça internacional de Rawls perde muito, em comparação com a teoria desenvolvida em suas obras anteriores, que colocava acima de qualquer arranjo ou sistema moral a inviolabilidade do indivíduo. Além disso, deve-se levar em conta que, no atual momento histórico, as condiçôes políticas e econômicas das sociedades nacionais são cada vez mais influenciadas por governos supranacionais e instituiçôes externas. Esse fato torna ainda mais necessário o desenvolvimento de um senso universal de justiça, capaz de influenciar as instituiçóes sociais que acabam por modelar a vida das pessoas.

Entretanto, apesar das críticas à sua concepção minimalista de direitos humanos, apresentadas neste artigo, Rawls propõe uma justificação filosófica de tais direitos bastante singular e importante aos dias de hoje. Se, por um lado, seus argumentos relativos ao plano internacional parecem não estar fortemente solidificados, nem enfrentar com profundidade os dilemas da atual realidade global, sua obra filosófica como um todo é plenamente capaz de propor uma justificação filosófica para uma relação de direitos essenciais para a defesa dos cidadãos. Assim, através da ideia de senso de justiça, fundamental na argumentação proposta em $A$ theory of justice e Political liberalism, a concepção de direitos humanos e fundamentais proposta por Rawls reafirma, no plano internacional, o ideal de reciprocidade essencial à sociedade política, garantindo-se não só a legitimidade de tais direitos, como a sua justiça.

FELDENS, Guilherme de Oliveira e KRETSCHMANN, Ângela. The Conception of Human and Fundamental Rights in theory of 'justice as fairness'. Tans/form/ação, Marília, v. 40, n. 4, p. 187-208, Out./Dez., 2017.

\footnotetext{
ABSTRACT. This article aims, at first, to analyze the conception of human rights by John Rawls, to verify that the minimalist and non-metaphysical conception presented by the author is able to offer, in present days, a moral ideal to serve as a basis for a democratic and fair international Society.
}

KEYWORDS. Human rights. Sense of justice. Fairness. 


\section{REFERÊNCIAS}

AUDARD, C. John Rawls. Montreal: McGill-Queen's University Press, 2007.

BARRETTO, V. P. O fetiche dos direitos humanos. Porto Alegre: Livraria do Advogado, 2013.

BEITZ, C. Political theory and international relations. Princeton: Princeton University Press, 1979.

. Liberalismo internacional e justiça distributiva. Lua Nova: cultura e política, São Paulo, n. 47, p. 27-58, mar. 1999.

BIELEFELDT, H. Filosofia dos direitos humanos. São Leopoldo, RS: Editora UNISINOS, 2000.

BUCHANAN, A. Rawls`s Law of Peoples. Ethics, v. 110, n. 4, p. 697-721, 2000.

FREEMAN, S. Rawls. New York: Routledge, 2007.

. (Org.). The Cambridge companion to rawls. Cambridge, Mass.: Cambridge University Press, 2001.

KÜNG, H. Uma ética global para a política e a economia mundiais. Rio de Janeiro: Vozes, 1999.

NEDEL, J. A teoria ético-politica de John Rawls: uma tentativa de integraçáo de liberdade e igualdade. Porto Alegre: EDIPUCRS, 2000.

OLIVEIRA, N. Rawls. Rio de Janeiro: Jorge Zahar, 2003.

PARIJS, P. Van. O que é uma sociedade justa? Introdução à prática da filosofia política. São Paulo: Ática, 1997.

. Difference principles. In: FREEMAN, S. (Ed.). The Cambridge companion to

Rawls. Cambridge, Mass.: Cambridge University Press, 2001. p. 200-240.

POGGE, T. Uma proposta de reforma: um dividendo global de recursos. Lua Nova: cultura e política, Sáo Paulo, v. 3, n. 34, p. 135-161, mar. 1994.

. John rawls. His life and theory of justice. New York: Oxford University Press, 2007.

RAWLS, J. Political liberalism. New York: Columbia University Press, 1996.

. A theory of justice. Cambridge, Mass.: Harvard University Press, 1999.

. The Law of peoples. Cambridge, Mass.: Harvard University Press, 2001.

. O direito dos povos. São Paulo: Martins Fontes, 2004.

. Uma teoria da justiça. São Paulo: Martins Fontes, 2008.

REIDY, D. Political authority and human rights. In: MARTIN, R.; REIDY, D. Rawls's law of peoples: a realistic utopia? Oxford: Blackwell, 2007. p. 169-188. 
RORTY, R. Verdade e progresso. São Paulo: Manole, 2005.

SEMPRINI, A. Multiculturalismo. São Paulo: EDUSC, 1999.

SEN, A. The idea of justice. Cambridge, Mass.: Harvard University Press, 2009.

VINCENT, R. J. Human rights and international relations. Cambridge: Cambridge University Press, 2001.

VITA, A. A tarefa prática da filosofia política em John Rawls. Lua Nova: cultura e política, São Paulo, n. 25, p. 5-24, jul.1992.

. Justiça distributiva: a crítica de Sen a Rawls. Dados, São Paulo, v. 43, n. 3, p. 471-496, mar. 1999.

Recebido em 12/01/2016

Aceito em 26/12/2016 
FELDENS, G. O.; KRETSCHMANN, Â 